\title{
Esophageal cancer in patients under 50: a SEER analysis
}

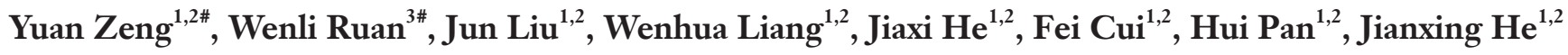 \\ ${ }^{1}$ Department of Thoracic Surgery, the First Affiliated Hospital of Guangzhou Medical University, Guangzhou 510120, China; ${ }^{2}$ Guangzhou Institute \\ of Respiratory Disease \& China State Key Laboratory of Respiratory Disease \& National Clinical Research Center for Respiratory Disease, \\ Guangzhou 510120, China; ${ }^{3}$ Department of Laboratory of Medicine, Guangzhou Zisheng Biotech, Guangzhou 510120, China \\ Contributions: (I) Conception and design: J He, Y Zeng; (II) Administrative support: J He, J Liu, W Liang; (III) Provision of study materials or \\ patients: Y Zeng, W Ruan; (IV) Collection and assembly of data: Y Zeng, W Ruan, J He, F Cui, H Pan; (V) Data analysis and interpretation: Y Zeng, \\ W Ruan, J Liu, W Liang; (VI) Manuscript writing: All authors; (VII) Final approval of manuscript: All authors. \\ \#These authors contributed equally to this work. \\ Correspondence to: Jianxing He, MD, PhD, FACS. Department of Thoracic Surgery, the First Affiliated Hospital of Guangzhou Medical University; \\ Guangzhou Institute of Respiratory Disease \& China State Key Laboratory of Respiratory Disease, No. 151, Yanjiang Rd, Guangzhou 510120, \\ China. Email: drjianxing.he@gmail.com.
}

Background: Concomitant with rising rates of esophageal adenocarcinoma, there has been a significant
increase of diagnoses among relatively younger individuals. However, most studies that focus on esophageal
cancer (EC) in younger patients have had small sample sizes of patients treated at a single institute. The aim
of this study was to analyze the clinical characteristics, outcomes and independent prognostic factors for EC
in patients under 50-year-old using a large, multi-center dataset. Methods: The national Surveillance, Epidemiology, and End Results (SEER) database was analyzed for EC reported from 2004 to 2013. Patients were divided into two groups, those under 50-year-old and those 50 years or older, and comparisons were made regarding demographics, histology, stage distribution, treatment, overall survival (OS), and esophageal cancer-specific survival (ECSS). Multivariate Cox proportional hazard regression analyses were also used to identify independent prognostic factors.

Results: Among the 16,544 eligible patients, 1,385 (8.37\%) were under 50 and 15,159 (91.63\%) were over 50. Compared with the older group, patients under 50 were characterized by a higher frequency of males, lower esophagus involvement, adenocarcinoma histology, stage III/IV disease, and receiving esophagectomy or radiation therapy. The stage-wise OS and ECSS were significantly better in the younger group $(\mathrm{P}<0.001)$. The multivariate analysis indicated that African-American heritage, grade III or IV, later stage, and not undergoing surgical or radiation therapy were independent negative prognostic factors of ECSS for patients under 50 .

Conclusions: EC patients under 50-year-old had distinctive clinicopathological characteristics compared with patients over 50-year-old. Despite more often presenting with stage III and IV disease, survival rates were better in the younger cohort. Prognostic factors for ECSS in patients under 50 differed from those in all age patients.

Keywords: Surveillance, Epidemiology, and End Results (SEER); esophageal cancer (EC); young patients

Submitted Mar 25, 2017. Accepted for publication May 04, 2018.

doi: $10.21037 /$ jtd.2018.05.72

View this article at: http://dx.doi.org/10.21037/jtd.2018.05.72

\section{Introduction}

There were approximately 455,800 new esophageal cancer (EC) diagnoses and 400,200 deaths due to the malignancy in 2012 (1), making it one of the most common cancers worldwide. In the United States there were an estimated 16,980 new EC diagnoses and 15,590 deaths in 2015 (2). Currently, the 5 -year survival rate of EC is approximately $20 \%(3)$. 
Recent studies have shown that increasing numbers of young patients are being diagnosed with EC, and predominantly esophageal adenocarcinoma (4-6). However, the clinical characteristics and outcomes for EC in the young population have not been well described. There are conflicting data on the distributions of histological subtype and clinical stage at diagnosis (7-9). Furthermore, the majority of published data regarding EC in young patients originate from single-institution retrospective studies, and it remains controversial whether young EC patients have better or worse outcomes than older patients (7-12). Additionally, most of these studies have used small numbers of young patients, and some have only evaluated patients with esophageal adenocarcinoma.

It is essential to determine if the clinical characteristics and/or survival rates of younger EC patients differs from older patients in a large-scale study. Therefore, the national Surveillance, Epidemiology and End Results (SEER) database, which collected EC patient data from 2004 to 2013 was used to study the clinical characteristics, outcomes and independent prognostic factors for EC in patients under 50 years old.

\section{Methods}

\section{Patients}

The SEER database is compiled by the National Cancer Institute and covers approximately $28 \%$ of the United States population. Ethical approval was obtained from participating institutions through their respective institutional review boards. We analyzed the SEER Cancer Incidence Public-Use Database that was submitted in November 2013, and data regarding EC (site codes C15.0C15.9) were extracted for the years 2004 to 2013. The exclusion criteria were records lacking microscopically confirmed diagnoses or diagnoses made during autopsy or by death certificate, records lacking age, race, or sex, site of cancer, differentiation grade, stage, surgery, radiation information, and those lacking patient survival times. All malignancies were staged according to the AJCC 6th edition. Surgery techniques included endoscopic treatment and esophagectomy; radiation included any method of radiation therapy.

A total of 16,544 EC patients matching the specified criteria were included in the final analysis. The individual data retrieved for each case included age at diagnosis, gender, race, year of diagnosis, site of cancer, differentiation grade, tumor histology, stage, treatment modality (radiotherapy/surgery), cause-specific death classification, vital status and survival time. Finally, the entire patient population was divided into two groups: less than 50 years and 50 years or older at diagnosis.

\section{Statistical analysis}

The Chi-square test was used to evaluate the statistical significance of differences in gender, race, year of diagnosis, site of cancer, differentiation grade, tumor histology, stage, and treatment modality among the two age groups. Overall survival (OS) was defined as the time from diagnosis to death from any cause, and patients that are currently alive were censored at the time of last recording. EC-specific survival (ECSS) was defined as the time from diagnosis to EC-related death. OS and ECSS were estimated using the Kaplan-Meier method and compared by log-rank test. Multivariate Cox proportional hazard regression was used to determine independent prognostic factors, and a hazard ratio (HR) and corresponding 95\% confidence interval (CI) were calculated. Statistical analyses were performed using SEER*stat and SPSS 20.0. All statistical tests were two sided and $\mathrm{P}<0.05$ was considered statistically significant.

\section{Results}

\section{Demographics}

A total of 16,544 patients met the entry criteria of this study. The median age was 65 -year-old, and the median [interquartile range (IQR)] follow-up time for ECSS was 9 [4-22] months. There were 1,385 patients $(8.37 \%)$ younger than 50 , and 15,159 patients $(91.63 \%)$ over 50 . The distribution of each age is shown in Figure S1. The proportion of women with EC was significantly lower in the younger group than in the older group $(15.2 \%$ vs. $19.1 \% ; \mathrm{P}<0.001)$. There was a higher proportion of African-Americans in the younger group than the older group $(11.3 \%$ vs. $9.6 \% ; \mathrm{P}<0.001)$. Additionally, there was a significantly lower proportion of young patients diagnosed in 2009-2013 compared with the previous years in the dataset $(47 \%$ vs. $51.4 \% ; \mathrm{P}<0.001)$ (Table 1).

\section{Site of cancer and Differentiation grade}

The distribution of cancer sites was significantly different between the younger and older groups. Lower esophagus 
Table 1 Description of the SEER population of patients with esophageal cancer by age at diagnosis

\begin{tabular}{|c|c|c|c|c|c|}
\hline \multirow{3}{*}{ Characteristic } & \multicolumn{4}{|c|}{ Age group (years) } & \multirow{3}{*}{$P$} \\
\hline & \multicolumn{2}{|c|}{$<50(\mathrm{n}=1,385)$} & \multicolumn{2}{|c|}{$\geq 50(n=15,159)$} & \\
\hline & No. & $\%$ & No. & $\%$ & \\
\hline Gender & & & & & $<0.001$ \\
\hline Male & 1,175 & 84.8 & 12,271 & 80.9 & \\
\hline Female & 210 & 15.2 & 2,888 & 19.1 & \\
\hline Race & & & & & 0.116 \\
\hline White & 1,161 & 83.8 & 12,977 & 85.6 & \\
\hline African-American & 157 & 11.3 & 1,458 & 9.6 & \\
\hline Other & 67 & 4.8 & 724 & 4.8 & \\
\hline Year & & & & & 0.002 \\
\hline 2004-2008 & 734 & 53 & 7,369 & 48.6 & \\
\hline 2009-2013 & 651 & 47 & 7,790 & 51.4 & \\
\hline Site of cancer & & & & & $<0.001$ \\
\hline $\begin{array}{l}\text { Upper } \\
\text { esophagus }\end{array}$ & 52 & 3.8 & 820 & 5.4 & \\
\hline $\begin{array}{l}\text { Middle } \\
\text { esophagus }\end{array}$ & 173 & 12.5 & 2,819 & 18.6 & \\
\hline $\begin{array}{l}\text { Lower } \\
\text { esophagus }\end{array}$ & 1,160 & 83.6 & 11,520 & 76 & \\
\hline Differentiation grade & & & & & 0.843 \\
\hline Grade I & 78 & 5.6 & 835 & 5.5 & \\
\hline Grade II & 544 & 39.3 & 6,075 & 40.1 & \\
\hline Grade III or IV & 763 & 55.1 & 8,249 & 54.4 & \\
\hline Histology & & & & & $<0.001$ \\
\hline Squamous & 285 & 20.6 & 4,350 & 28.7 & \\
\hline Adenocarcinoma & 1,004 & 72.5 & 9,953 & 65.7 & \\
\hline Others & 96 & 6.9 & 856 & 5.6 & \\
\hline Stage & & & & & $<0.001$ \\
\hline I & 127 & 9.2 & 2,568 & 16.9 & \\
\hline ॥ & 247 & 17.8 & 3,283 & 21.7 & \\
\hline III & 339 & 24.5 & 3,559 & 23.5 & \\
\hline IV & 672 & 48.5 & 5,749 & 37.9 & \\
\hline Surgery & & & & & $<0.001$ \\
\hline Endoscopic & 18 & 1.3 & 383 & 2.5 & \\
\hline Esophagectomy & 500 & 36.1 & 4,450 & 29.4 & \\
\hline No & 867 & 62.6 & 10,326 & 68.1 & \\
\hline
\end{tabular}

Table 1 (continued)
Table 1 (continued)

\begin{tabular}{|c|c|c|c|c|c|}
\hline \multirow{3}{*}{ Characteristic } & \multicolumn{4}{|c|}{ Age group (years) } & \multirow{3}{*}{$\mathrm{P}$} \\
\hline & \multicolumn{2}{|c|}{$<50(\mathrm{n}=1,385)$} & \multicolumn{2}{|c|}{$\geq 50(n=15,159)$} & \\
\hline & No. & $\%$ & No. & $\%$ & \\
\hline Radiation therapy & & & & & 0.341 \\
\hline Yes & 842 & 60.8 & 9,017 & 59.5 & \\
\hline No & 543 & 39.2 & 6,142 & 40.5 & \\
\hline
\end{tabular}

involvement was more prevalent in patients under 50 (83.6\% vs. $76 \% ; \mathrm{P}<0.001)$. In contrast, upper and middle esophageal disease were more prevalent in the older group (3.8\% vs. $5.4 \% ; \mathrm{P}<0.001$; and $12.5 \%$ vs. $18.6 \% ; \mathrm{P}<0.001$, respectively). Additionally, there was no significant difference in the differentiation grades between patients under 50 and patients over $50(\mathrm{P}=0.843)$.

\section{Histology and staging}

There were considerable differences in the distribution of tumor histologies between the two groups. Most strikingly, adenocarcinoma cases were more prevalent in the younger patients $(72.5 \%$ vs. $65.7 \%$; $\mathrm{P}<0.001)$. In contrast, squamous cell carcinoma accounted for $20.6 \%$ of patients under 50 , but $28.7 \%$ of patients over $50(\mathrm{P}<0.001)$. The distribution of tumor staging was also significantly different between the two groups. The younger group had a higher proportion of stage III and IV disease than the older group, whereas the older group had a higher proportion of patients with stage I and II disease $(\mathrm{P}<0.001)$ (Table 1).

\section{Therapy}

The use of surgery and radiation therapy was also significantly different between the two groups. The proportion of patients that underwent esophagectomy was significantly higher in younger group $(36.1 \%)$ than the older group (29.4\%) $(\mathrm{P}<0.001) ; 1.3 \%$ of the younger group and $2.5 \%$ of the older group received endoscopic therapy $(\mathrm{P}<0.001)$. However, there was no difference in radiation therapy $(\mathrm{P}=0.341)$.

\section{Survival and prognostic factors}

The stage-wise, overall and cancer-specific survival rates 
A
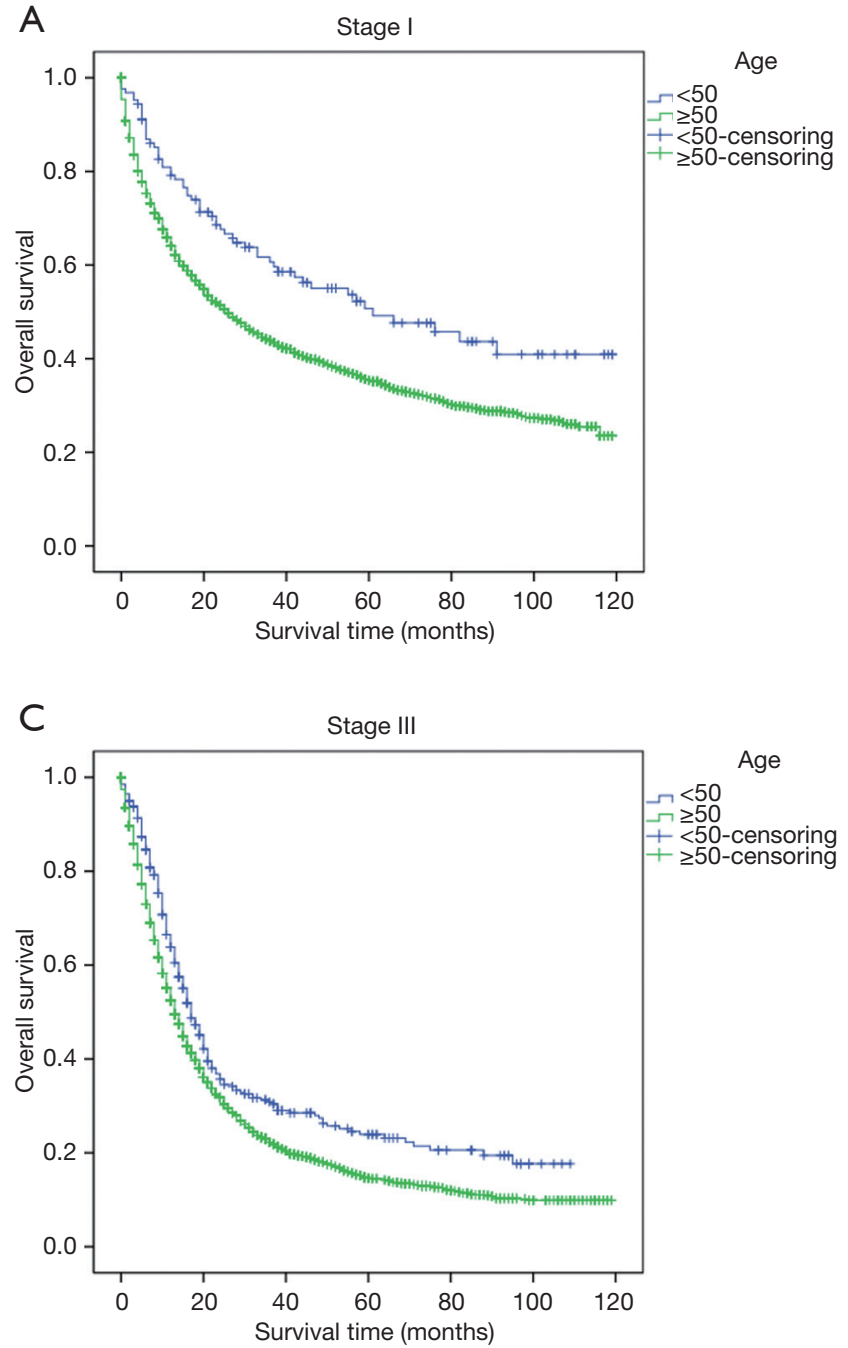
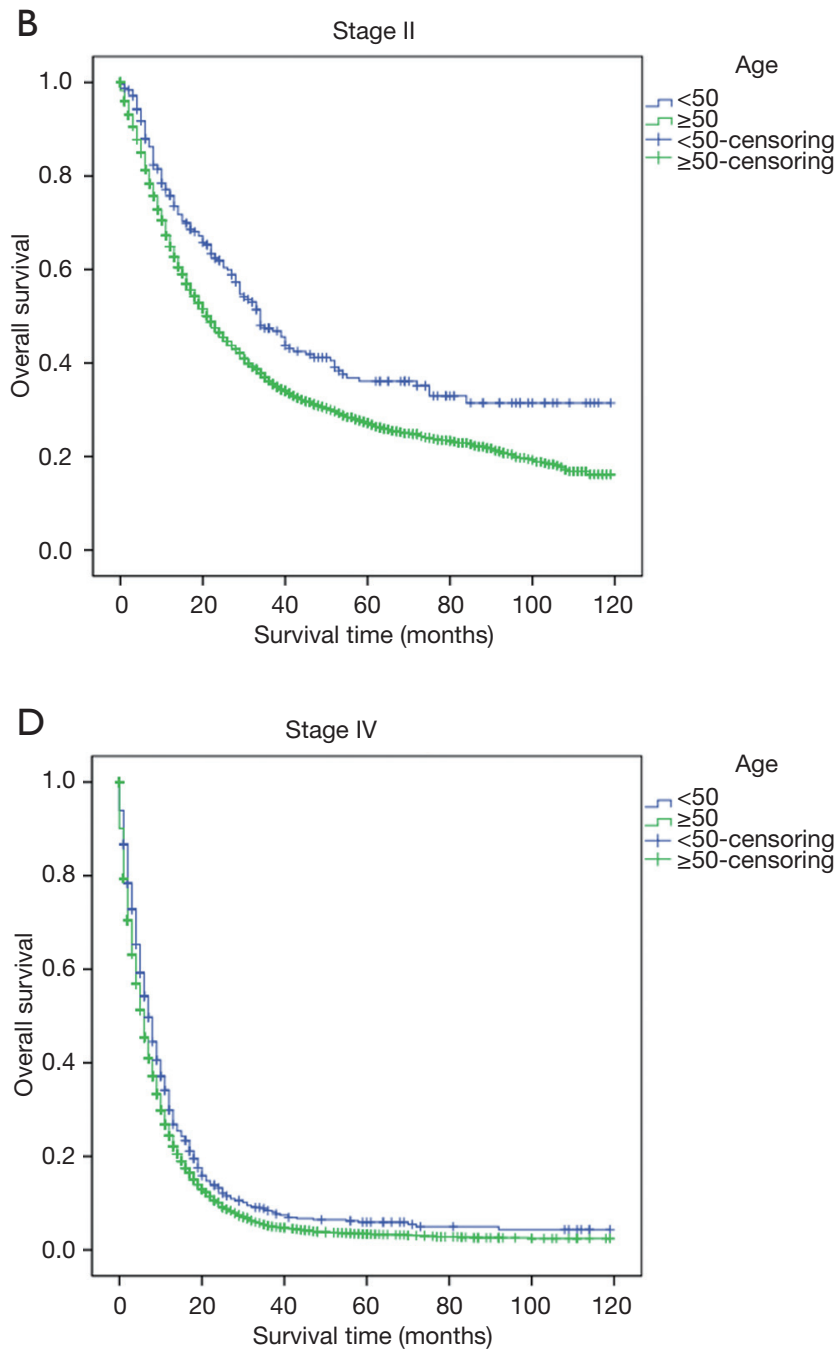

Figure 1 Kaplan-Meier curves comparing stage-wise overall survival between patients under 50 years and patients 50 years or older.

were higher for younger patients than older patients $(\mathrm{P}<0.001$; Figures 1,2). A multivariate analysis was performed to control for the effects of age, race, year of diagnosis, histology, site of cancer, differentiation grade, tumor stage and treatment modality on ECSS (Table 2). The results of the multivariate analysis indicated that age $<50$ years was an independent predictor of improved ECSS (HR: 0.881; 95\% CI: $0.824-0.943 ; \mathrm{P}<0.001)$. The independent HR of death was highest for patients with stage IV disease (HR: 2.681; 95\% CI: 2.504-2.870; $\mathrm{P}<0.001)$. AfricanAmericans (HR: 1.134; 95\% CI: 1.061-1.212; P<0.001), patients with squamous cell carcinoma (HR: $1.059 ; 95 \%$ CI: 1.002-1.119; $\mathrm{P}<0.001$ ), grade III or IV (HR: $1.631 ; 95 \%$ CI: $1.475-1.802 ; \mathrm{P}<0.001)$ and year of diagnosis between
2004 and 2008 (HR: 1.193; 95\% CI: 1.148-1.240; P<0.001) were also significant independent negative prognostic factors. Patients with Endoscopic therapy (HR: 0.306; 95\% CI: 0.254-0.369; $\mathrm{P}<0.001$ ) or Esophagectomy (HR: 0.346; 95\% CI: $0.328-0.365 ; \mathrm{P}<0.001)$ and radiation therapy (HR: 0.634; 95\% CI: $0.609-0.660 ; \mathrm{P}<0.001$ ) were significant independent predictors of improved ECSS (Table 2).

In the group of younger patients, the multivariate analysis indicated that significant independent negative prognostic factors included African-American (HR: 1.508; 95\% CI: 1.238-1.837; $\mathrm{P}<0.001$ ), grade III or IV (HR: 2.073; 95\% CI: $1.456-2.953 ; \mathrm{P}<0.001)$, later stage $(\mathrm{P}<0.001)$. Moreover, endoscopic treatment (HR: 0.261; 95\% CI: 0.096-0.708; $\mathrm{P}<0.001$ ), esophagectomy (HR: 0.323; 95\% 
A
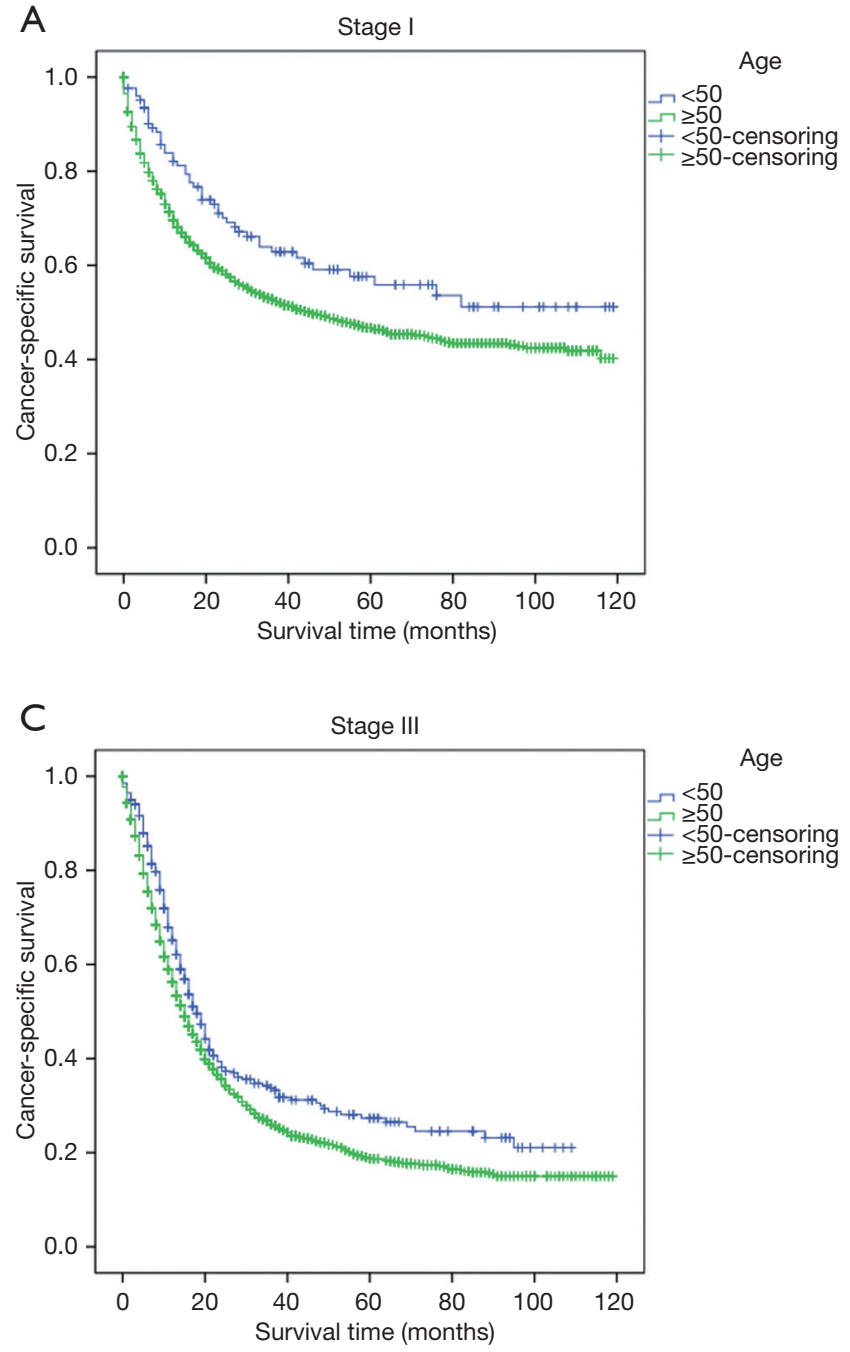
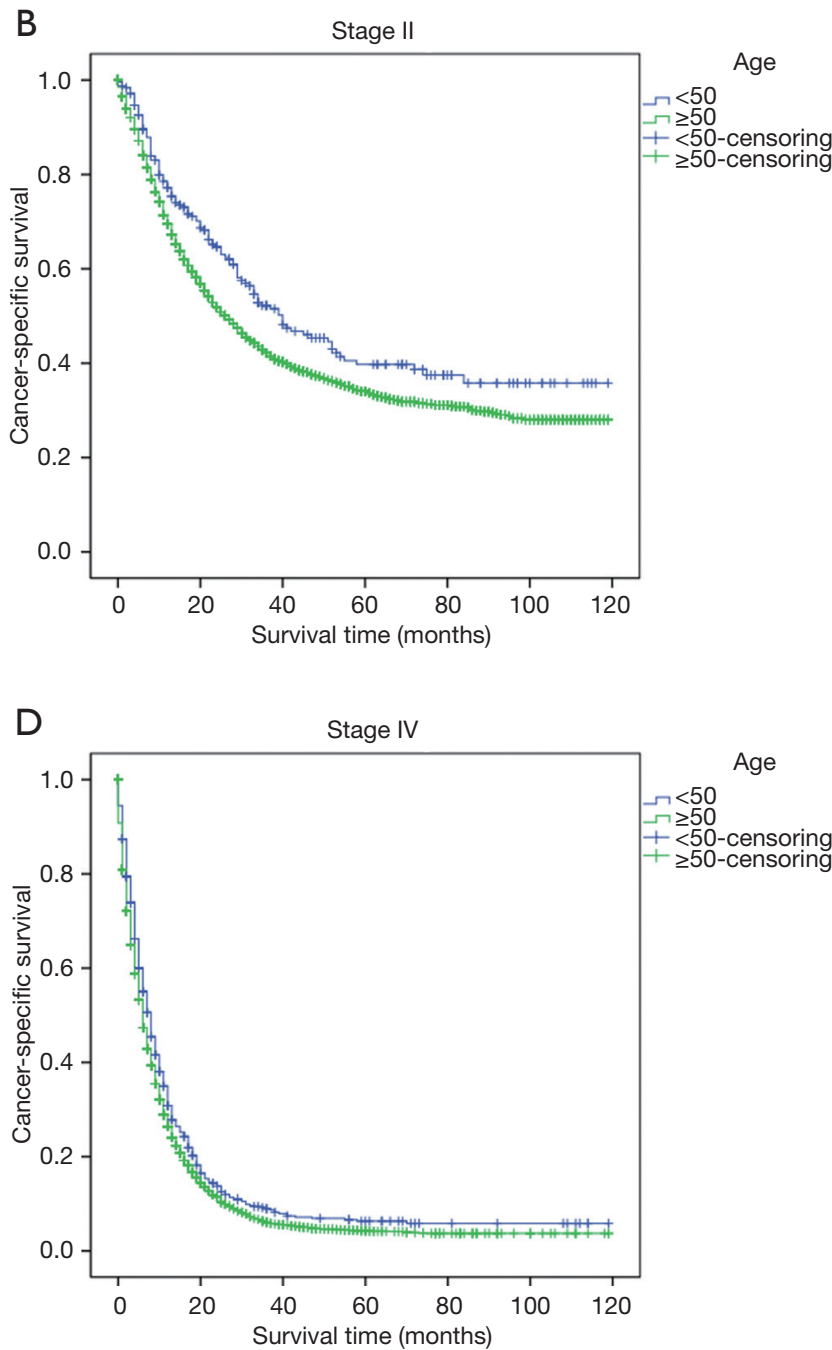

Figure 2 Kaplan-Meier curves comparing stage-wise esophageal cancer-specific survival between patients under 50 years and patients 50 years or older.

CI: $0.270-0.386 ; \mathrm{P}<0.001)$ and radiation therapy (HR: 0.799; 95\% CI: 0.696-0.917; $\mathrm{P}<0.001)$ were significant independent predictors of improved ECSS (Table 3).

\section{Discussion}

There has been a concomitant increase in EC diagnoses in younger patients along with the increased numbers of total esophageal adenocarcinoma diagnoses (6). This is a concern for clinicians because little is known about the clinicopathological characteristics and outcomes for EC in younger patients. Patients under 50-year-old have been considered the young patient cohort in many studies focused on EC $(7,8,10,13,14)$ and other cancers $(15,16)$. In this study, an analysis of the SEER database revealed that EC patients under 50 had distinctive clinicopathological characteristics and better survival outcomes compared to older patients. In addition, a multivariate analysis was also performed to identify independent prognostic factors in patients under 50 .

A previous study compared EC in three age groups: under 49, between 50 and 69, and over 70 years (10). There were no significant differences among the three groups with regard to sex ratio, histological subtype, TNM classification or lymph node metastasis. In a separate report, Adam et al. reported esophagogastrectomy results in patients under 50 years compared with those between 50 and 69 or over 70 years (7). Again, no significant differences 
Table 2 Multivariable analysis of ECSS in SEER population of patients with esophageal cancer

\begin{tabular}{|c|c|c|c|c|}
\hline \multirow{2}{*}{ Characteristic } & \multirow{2}{*}{$\begin{array}{c}\text { Univariable } \\
\text { analysis } \\
\text { (P) }\end{array}$} & \multicolumn{3}{|c|}{ Multivariable analysis } \\
\hline & & Hazard ratio & $95 \% \mathrm{Cl}$ & $\mathrm{P}$ \\
\hline Age & $<0.001$ & & & \\
\hline$<50$ & & 0.881 & $0.824-0.943$ & $<0.001$ \\
\hline$\geq 50$ & & 1 (reference) & & \\
\hline Gender & 0.259 & & & \\
\hline Male & & & & \\
\hline Female & & & & \\
\hline Race & $<0.001$ & & & \\
\hline White & & 1 (reference) & & \\
\hline $\begin{array}{l}\text { African- } \\
\text { American }\end{array}$ & & 1.134 & $1.061-1.212$ & $<0.001$ \\
\hline other & & 0.937 & $0.856-1.025$ & 0.155 \\
\hline Year & $<0.001$ & & & \\
\hline 2004-2008 & & 1.193 & $1.148-1.240$ & $<0.001$ \\
\hline 2009-2013 & & 1 (reference) & & \\
\hline Site of cancer & $<0.001$ & & & \\
\hline $\begin{array}{l}\text { Upper } \\
\text { esophagus }\end{array}$ & & 1 (reference) & & \\
\hline $\begin{array}{l}\text { Middle } \\
\text { esophagus }\end{array}$ & & 1.095 & $0.999-1.200$ & 0.052 \\
\hline $\begin{array}{l}\text { Lower } \\
\text { esophagus }\end{array}$ & & 1.022 & $0.933-1.120$ & 0.635 \\
\hline $\begin{array}{l}\text { Differentiation } \\
\text { grade }\end{array}$ & $<0.001$ & & & \\
\hline Grade I & & 1 (reference) & & \\
\hline Grade II & & 1.301 & $1.175-1.440$ & $<0.001$ \\
\hline Grade III or IV & & 1.631 & $1.475-1.802$ & $<0.001$ \\
\hline Histology & $<0.001$ & & & \\
\hline Squamous & & 1.059 & $1.002-1.119$ & 0.042 \\
\hline Adenocarcinoma & & 1 (reference) & & \\
\hline Others & & 1.115 & $1.030-1.207$ & 0.007 \\
\hline Stage & $<0.001$ & & & \\
\hline 1 & & 1 (reference) & & \\
\hline II & & 1.308 & $1.213-1.410$ & $<0.001$ \\
\hline III & & 2.015 & $1.875-2.166$ & $<0.001$ \\
\hline IV & & 2.681 & 2.504-2.870 & $<0.001$ \\
\hline
\end{tabular}

Table 2 (continued)
Table 2 (continued)

\begin{tabular}{|c|c|c|c|c|}
\hline \multirow{2}{*}{ Characteristic } & \multirow{2}{*}{$\begin{array}{c}\text { Univariable } \\
\text { analysis } \\
\text { (P) }\end{array}$} & \multicolumn{3}{|c|}{ Multivariable analysis } \\
\hline & & Hazard ratio & $95 \% \mathrm{Cl}$ & $P$ \\
\hline Surgery & $<0.001$ & & & \\
\hline Endoscopic & & 0.306 & $0.254-0.369$ & $<0.001$ \\
\hline Esophagectomy & & 0.346 & $0.328-0.365$ & $<0.001$ \\
\hline No & & 1 (reference) & & \\
\hline Radiation therapy & $<0.001$ & & & \\
\hline Yes & & 0.634 & $0.609-0.660$ & $<0.001$ \\
\hline No & & 1 (reference) & & \\
\hline
\end{tabular}

NOS, not otherwise specified; ECSS, esophageal cancerspecific survival; $\mathrm{CI}$, confidence interval; SEER, Surveillance, Epidemiology, and End Results.

were found in tumor pathology, stage, extent of resection, hospital mortality or survival. However, we report that EC patients under 50 are characterized by a higher proportion of male, African-Americans, lower esophageal disease, adenocarcinomas and later stages (III and IV) compared with older patients. Most strikingly, younger patients were more likely to have adenocarcinomas, which account for $72.5 \%$ of all diagnoses in this age group. Markar et al. (8) also found that patients under 50 years were more likely to have esophageal adenocarcinoma. This phenomenon may be related to obesity, chronic gastroesophageal reflux disease, smoking or a low intake of fruits and vegetables, which are the main risk factors for esophageal adenocarcinoma (1).

We performed stage-wise comparisons of OS and ECSS between the two groups, and the results showed that EC patients under 50 years old at diagnosis have significantly better OS and ECSS than older patients, despite more patients in the younger group presenting with more advanced-staged disease. This is consistent with the findings of Vallböhmer et al., who reported that the 5-year survival rate of younger patients was significantly higher than elderly patients (12). However, several studies have suggested that there are no differences in the clinical characteristics or survival rates of younger or older EC patients $(7,8,10,14)$. These studies may not have obtained statistically significant results due to small patient cohorts. In addition, a separate study indicated that younger esophageal adenocarcinoma patients had a poorer prognosis due to delayed diagnoses and more advanced disease (13).

Notably, we also identified age under 50 as an independent 
Table 3 Multivariable analysis of ECSS in SEER population of patients under 50 with esophageal cancer

\begin{tabular}{|c|c|c|c|c|}
\hline \multirow{2}{*}{ Characteristic } & \multirow{2}{*}{$\begin{array}{c}\text { Univariable } \\
\text { analysis } \\
\text { (P) }\end{array}$} & \multicolumn{3}{|c|}{ Multivariable analysis } \\
\hline & & Hazard ratio & $95 \% \mathrm{Cl}$ & $\mathrm{P}$ \\
\hline Age & 0.964 & & & \\
\hline$<40$ & & & & \\
\hline$\geq 40$ & & & & \\
\hline Gender & 0.641 & & & \\
\hline Male & & & & \\
\hline Female & & & & \\
\hline Race & 0.001 & & & \\
\hline White & & 1 (reference) & & \\
\hline African-American & & 1.508 & $1.238-1.837$ & $<0.001$ \\
\hline Other & & 0.999 & $0.723-1.380$ & 0.995 \\
\hline Year & 0.114 & & & \\
\hline 2004-2008 & & & & \\
\hline 2009-2013 & & & & \\
\hline Site of cancer & 0.369 & & & \\
\hline $\begin{array}{l}\text { Upper } \\
\text { esophagus }\end{array}$ & & & & \\
\hline $\begin{array}{l}\text { Middle } \\
\text { esophagus }\end{array}$ & & & & \\
\hline $\begin{array}{l}\text { Lower } \\
\text { esophagus }\end{array}$ & & & & \\
\hline $\begin{array}{l}\text { Differentiation } \\
\text { grade }\end{array}$ & $<0.001$ & & & \\
\hline Grade I & & 1 (reference) & & \\
\hline Grade II & & 1.524 & $1.064-2.184$ & 0.022 \\
\hline Grade III or IV & & 2.073 & $1.456-2.953$ & $<0.001$ \\
\hline Histology & 0.163 & & & \\
\hline Squamous & & & & \\
\hline Adenocarcinoma & & & & \\
\hline Others & & & & \\
\hline Stage & $<0.001$ & & & \\
\hline 1 & & 1 (reference) & & \\
\hline II & & 1.454 & $1.033-2.046$ & 0.032 \\
\hline III & & 2.217 & $1.602-3.067$ & $<0.001$ \\
\hline IV & & 2.96 & $2.163-4.051$ & $<0.001$ \\
\hline
\end{tabular}

Table 3 (continued)
Table 3 (continued)

\begin{tabular}{|c|c|c|c|c|}
\hline \multirow{2}{*}{ Characteristic } & \multirow{2}{*}{$\begin{array}{c}\text { Univariable } \\
\text { analysis } \\
\text { (P) }\end{array}$} & \multicolumn{3}{|c|}{ Multivariable analysis } \\
\hline & & Hazard ratio & $95 \% \mathrm{Cl}$ & $\mathrm{P}$ \\
\hline Surgery & $<0.001$ & & & \\
\hline Endoscopic & & 0.261 & $0.096-0.708$ & 0.008 \\
\hline Esophagectomy & & 0.323 & $0.270-0.386$ & $<0.001$ \\
\hline No & & 1 (reference) & & \\
\hline Radiation therapy & $<0.001$ & & & \\
\hline Yes & & 0.799 & $0.696-0.917$ & $<0.001$ \\
\hline No & & 1 (reference) & & \\
\hline
\end{tabular}

prognostic factor for better ECSS. This is similar to a report of a SEER analysis (17), in which age under 45 was found to be a better prognostic factor among all EC patients. The main reason behind these results may be related to the fact that younger patients tend to receive more aggressive treatments than older patients. Vallböhmer et al. have also reported that younger patients presented with significantly lower comorbidities and received more radio-neoadjuvant therapy (12). We also found that adenocarcinomas were associated with better survival rates than squamous cell carcinomas. This result suggested that younger EC patients are more likely to have adenocarcinoma, and therefore their prognosis is better than that of the older group. Furthermore, we found that younger patients were more likely to receive esophagectomy or radiotherapy. Mori et al. (10) also concluded that the rate of hospital death is significantly lower in younger patients compared with older patients. Therefore, younger patients are more likely to receive more aggressive therapy than older patients because they generally have a better medical performance status.

The multivariate analysis revealed that African-American heritage, grade III or IV, later stage and no surgical or radiation therapy were independent predictors of poor survival in both patients of all ages and those under 50 years. African-American patients had poorer survival rates than white patients, probably because they were less likely to undergo surgery (18) and were associated with lower socioeconomic status $(19,20)$. Moreover, in younger patients, age, gender, year of diagnosis and histology 
were not independent prognostic factors as they were in the overall EC population. The explanations for these differences are unclear, but it is possible that there were differences in the distribution of histologies across age groups or molecular markers across histologic subtypes that may have influenced prognosis (21).

There were some limitations in this study. First, it was a retrospective study that may result in certain biases. Second, the SEER database cannot collect all relevant clinical information to control for potential confounding variables, such as detailed treatment data, comorbidities, socioeconomic status, or known risk factors such as smoking and alcohol consumption. Furthermore, we also were unable to analyze some important factors such as chemotherapy and recurrence data on disease outcomes. Finally, these results may not be generalized to countries other than United States of America because ECs in the other countries may have a different distribution of histological types and may result from different environmental or genetic factors that are endemic to different ethnic backgrounds. Despite these limitations, SEER analysis provides a suitable opportunity to analyze a large number of patients under 50, especially since the majority of published data involving EC in younger patients were originated from single-institute retrospective studies with rather small patient numbers.

In conclusion, patients under 50 years old account for $8.37 \%$ of all EC cases and had distinctive clinicopathological characteristics compared to older patients. Despite presenting with stage III and IV disease more often, survival rates were better in the younger cohort. Additionally, prognostic factors for ECSS differed from those in the overall EC population. Finally, more investigations are needed to provide adequate data regarding young EC patients.

\section{Acknowledgements}

We thank "International Science Editing" for helping to edit the manuscript.

\section{Footnote}

Conflicts of Interest: The authors have no conflicts of interest to declare.

Ethical Statement: The study was approved by participating institutions through their respective institutional review boards.

\section{References}

1. Torre LA, Bray F, Siegel RL, et al. Global cancer statistics, 2012. CA Cancer J Clin 2015;65:87-108.

2. Siegel RL, Miller KD, Jemal A. Cancer statistics, 2015. CA Cancer J Clin 2015;65:5-29.

3. Pennathur A, Gibson MK, Jobe BA, et al. Oesophageal carcinoma. Lancet 2013;381:400-12.

4. Guardino JM, Khandwala F, Lopez R, et al. Barrett's esophagus at a tertiary care center: association of age on incidence and prevalence of dysplasia and adenocarcinoma. Am J Gastroenterol 2006;101:2187-93.

5. Post PN, Siersema PD, Van Dekken H. Rising incidence of clinically evident Barrett's oesophagus in The Netherlands: a nation-wide registry of pathology reports. Scand J Gastroenterol 2007;42:17-22.

6. El-Serag HB, Mason AC, Petersen N, et al. Epidemiological differences between adenocarcinoma of the oesophagus and adenocarcinoma of the gastric cardia in the USA. Gut 2002;50:368-72.

7. Adam DJ, Craig SR, Sang CT, et al. Oesophagogastrectomy for carcinoma in patients under 50 years of age. J R Coll Surg Edinb 1996;41:371-3.

8. Markar SR, Karthikesalingam A, Low DE. Outcomes assessment of the surgical management of esophageal cancer in younger and older patients. Ann Thorac Surg 2012;94:1652-8.

9. Oezcelik A, Ayazi S, DeMeester SR, et al. Adenocarcinoma of the esophagus in the young. J Gastrointest Surg 2013;17:1032-5.

10. Mori M, Ohno S, Tsutsui S, et al. Esophageal carcinoma in young patients. Ann Thorac Surg 1990;49:284-6.

11. Patil PK, Patel SG, Mistry RC, et al. Cancer of the esophagus in young adults. J Surg Oncol 1992;50:179-82.

12. Vallböhmer D, Holscher AH, Brabender J, et al. Clinicopathologic and prognostic factors of young and elderly patients with esophageal adenocarcinoma: is there really a difference. Dis Esophagus 2008;21:596-600.

13. Portale G, Peters JH, Hsieh CC, et al. Esophageal adenocarcinoma in patients $<$ or $=50$ years old: delayed diagnosis and advanced disease at presentation. Am Surg 2004;70:954-8.

14. Kasagi $Y$, Morita M, Otsu H, et al. Clinicopathological characteristics of esophageal squamous cell carcinoma in patients younger than 50 years. Ann Surg Oncol 2015;22:311-5.

15. Ramalingam S, Pawlish K, Gadgeel S, et al. Lung cancer in young patients: analysis of a Surveillance, Epidemiology, 
and End Results database. J Clin Oncol 1998;16:651-7.

16. Lara MS, Brunson A, Wun T, et al. Predictors of survival for younger patients less than 50 years of age with nonsmall cell lung cancer (NSCLC): a California Cancer Registry analysis. Lung Cancer 2014;85:264-9.

17. Njei B, McCarty TR, Birk JW. Trends in esophageal cancer survival in United States adults from 1973 to 2009: a SEER database analysis. J Gastroenterol Hepatol 2016;31:1141-6.

18. Revels SL, Morris AM, Reddy RM, et al. Racial disparities in esophageal cancer outcomes. Ann Surg Oncol

Cite this article as: Zeng Y, Ruan W, Liu J, Liang W, He J, Cui F, Pan H, He J. Esophageal cancer in patients under 50: a SEER analysis. J Thorac Dis 2018;10(5):2542-2550. doi: 10.21037/jtd.2018.05.72
2013;20:1136-41.

19. Manfredi C, Kaiser K, Matthews AK, et al. Are racial differences in patient-physician cancer communication and information explained by background, predisposing, and enabling factors. J Health Commun 2010;15:272-92.

20. Morris AM, Rhoads KF, Stain SC, et al. Understanding racial disparities in cancer treatment and outcomes. J Am Coll Surg 2010;211:105-13.

21. Hong L, Han Y, Zhang H, et al. Prognostic markers in esophageal cancer: from basic research to clinical use. Expert Rev Gastroenterol Hepatol 2015;9:887-9. 


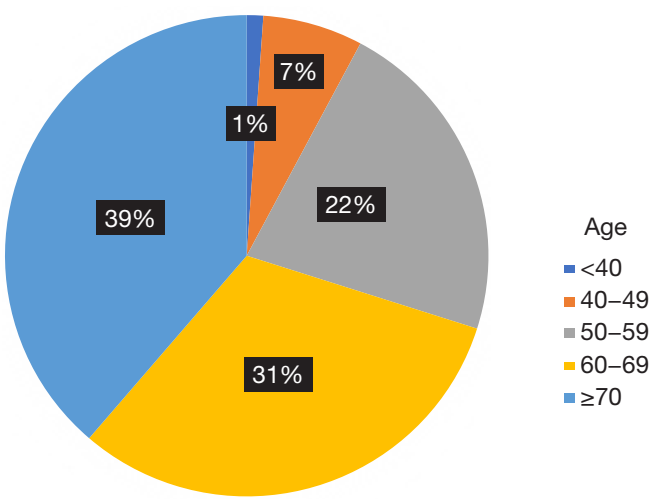

Figure S1 The distribution of each age. 